copolymers in order to create a new material with different physical properties is called polymer blend [10-14]. Some polymers when used alone, such as polystyrene, polyvinyl acetate or polychloroprene, are unable to render a superhydrophobic surface. Using binary mixtures of these two types of polymers in a single common solvent as a polymer blend, superhydrophobic composite surfaces can be created [15]. The reasons for the uneven distribution of nanofillers in polymer blends are considered and the parameters with which one can play to produce a desired morphology are identified [16]. The most important factor for improving the performance of polymer blends is choosing the right materials. For having PET wastes to be usable, blending with another polymer can be used.

Acrylonitril-Butadiene styrene (ABS) is an engineering plastic and it has butadiene part uniformly distributed over the acrylonitrile-styrene matrix. ABS characterizations are: excellent toughness, stable dimensionality, easy processing ability, chemical resistance, and cheapness [17-21]. The effect of layer orientation on the fracture properties of (ABS) materials fabricated through the fused filament fabrication (FFF) process was explored. Results show that the inter-laminar fracture toughness (fracture between layers) is approximately one order of magnitude lower than the cross-laminar toughness (fracture through layers) of similarly manufactured parts [22]. In an article, the microstructural design and short carbon fiber/acrylonitrile-butadiene-styrene (ABS) preforms and composite are explored and the compressive behavior of a 3D orthogonal, short carbon fiber/ABS preform and that of its silicone infused composite are characterized [23].

The blending of two different polymers offers the potential of providing a material with the advantages of each. Novel blends of PET and ABS were prepared by extrusion and injection molding [24]. In another study, the effect of processing temperature on the low-speed tensile and high-speed impact properties of novel ABS/PET blends was investigated. Due to the continuous structure of the blend, the hydrolytic or thermomechanical degradation of the PET resulted in a dramatic loss in mechanical properties which explained by the entanglement theory for fracture and the Orowan brittle-ductile hypothesis [25]. In another study, waste PET from thin bottles was blended with (ABS) copolymer in different proportions, up to 10 wt $\%$. Flexural modulus remained unaffected, although a slight decrease in impact property was observed [26].

Adding ABS to the PET is noteworthy in terms of commercial and scientifical. With adding PET to ABS not only mechanical properties of $A B S$ but also thermal properties of the polymer improve. In preparation of this polymer PET wastes can also be used and according to the massive volume of PETW and having low cost, it has its importance.

In this research, according to the large amount of PETW which are prepared in different petrochemical plants and in order to solve the environmental problem and improving the quality of the ABS polymer, in different conditions of temperature, time and speed of extruder, different percentages of PET Waste in ABS has been mixed for the first time in this article. Different tests (Impact Test, Elongation at Break, Modular Melt Flow, vicat softening temperature and Yellow Index) has been done on prepared polymer. In order to be a complete reference even in points which tests are not done, the results of these tests are simulated by the MLP method of ANN. According to the test results, an intended quality polymer is accessible by choosing correct PETw/ABS
Fig. 1 The regularization network
Activation Functions

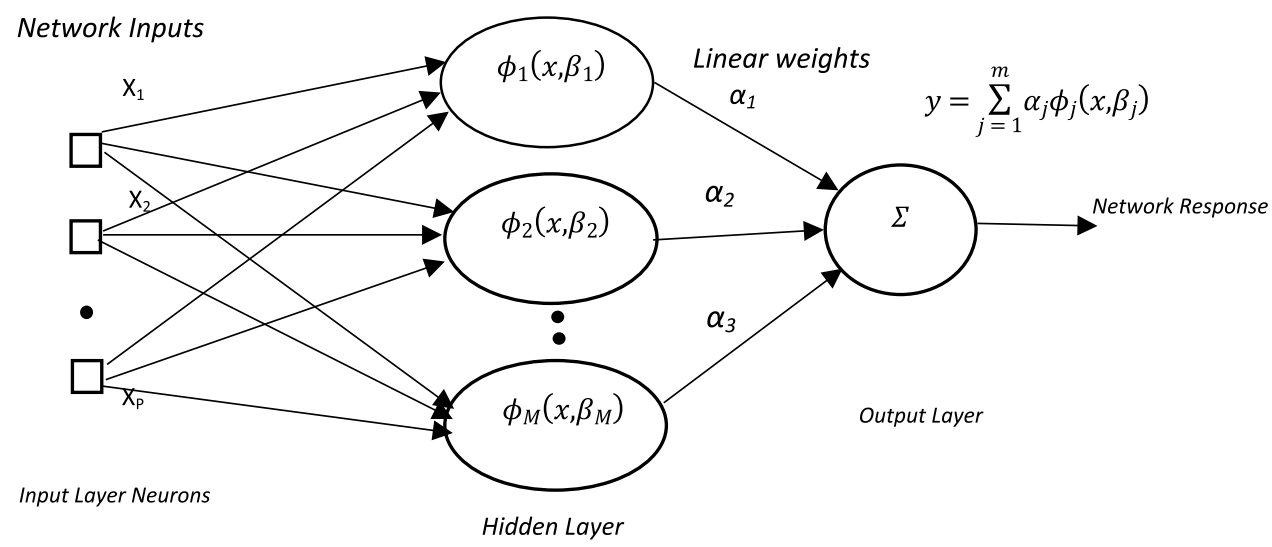


weight percentage and mixing conditions which, so far, no study has been done in this field.

\section{Materials and equipment}

\subsection{Materials}

Acrylo nitril-Butadiene styrene (ABS) obtained from Tabriz Petrochemical Company. PET wastes which has been used in Tabriz Petrochemical Company are used for this project.

\subsection{Equipment}

Twin screw extruder from SM Platek with screw diameter of $20 \mathrm{~mm}$ and length to diameter ratio of 32 has been used in order to mix polymeric materials. In order to prepare molds needed for elongation at break and impact tests, injection device with extruder temperature of $190^{\circ} \mathrm{C}$, injection pressure of 160 bar, injection volume of 3116 $\mathrm{cm}^{2}$ and template volume of $253 \mathrm{~cm}^{2}$ from Billion, France has been used. In order to investigate the elongation at break test for the samples, SHIMADZU Autograph AG-X

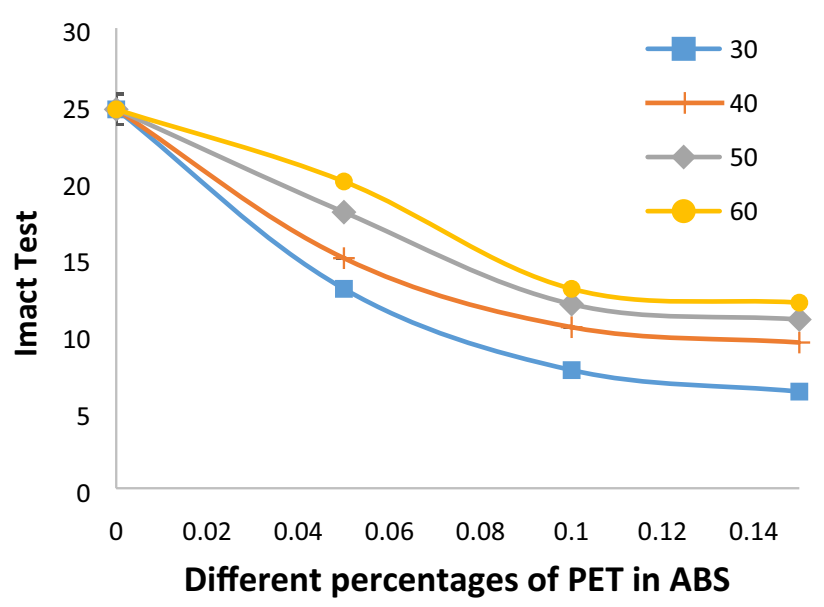

Fig. 3 Results of Impact Test for different percentages of PET in ABS of the polymer mixture in different mixing speed

with ASTM D-638 has been used. For investigating impact test, coded 6967.00 from Ceast, Italy with ASTM D-256 was used. In order to investigate the processability of prepared mixture and index of flow of mixtures coded 7026.00 from Ceast, Italy with ASTM D-1238 was used. In order to declare the softening point of materials without specified melting point, HD-PC from Yasuda, Japan with ASTM D-1525 has been used. Spectral radiation device SF450 model
Fig. 2 Learning algorithm for MLP Networks

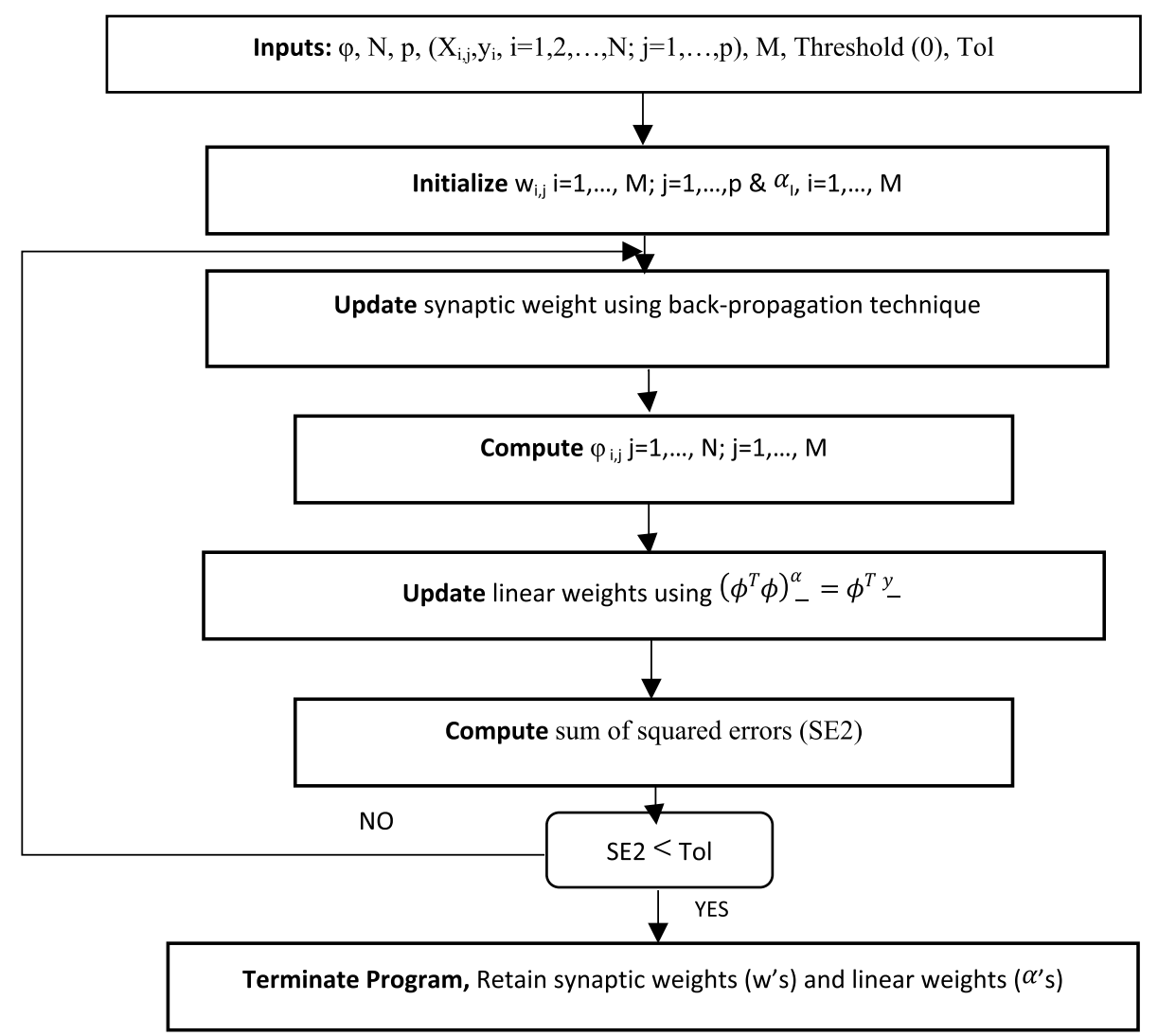

SN Applied Sciences 


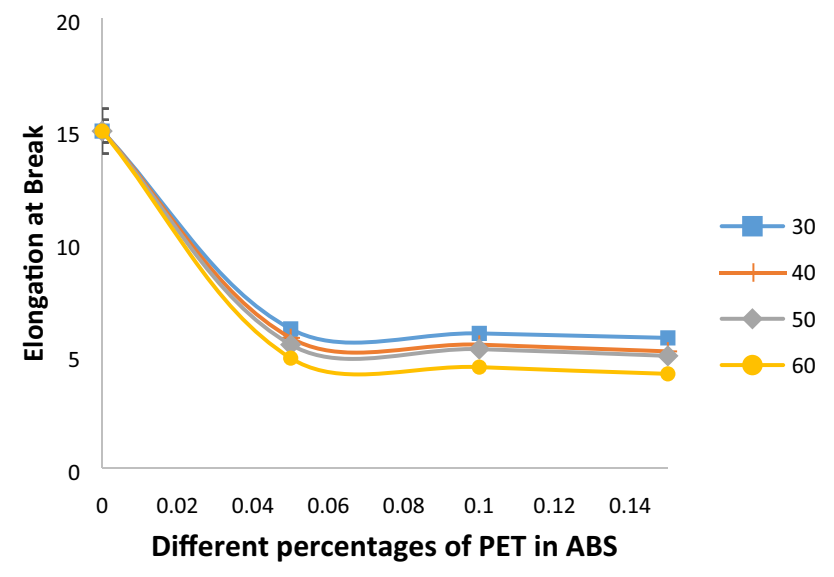

Fig. 4 Results of Elongation at Break Test for different percentages of PET in ABS of the polymer mixture in different mixing speed

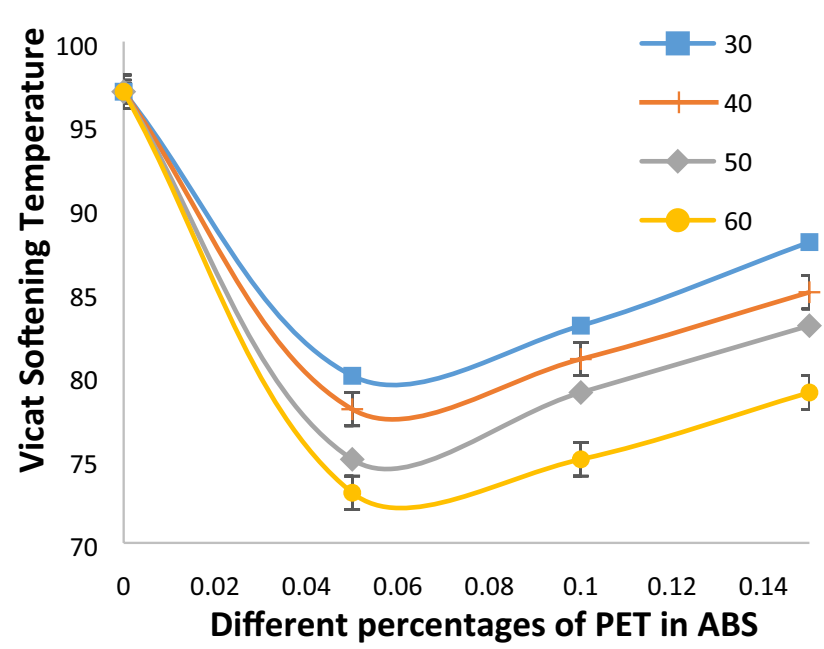

Fig. 5 Results of Vicat Softening Temperature Test for different percentages of PET in ABS of the polymer mixture in different mixing speed

for declaring yellow index with ASTM E-313 was used for measurement of the color coordinates of CIELAB and declaring yellow index of the mixtures. In order to know the concentration of the residual monomer in the samples Varian 3800 CP Gas Chromatographer was used.

\subsection{Methods}

Different amounts of PET wastes $(0,5,10$, and $15 \% w t)$ in $A B S$ in Extruder device with different mixing speeds (30, 40,50 , and 60rpn) and different mixing temperatures (200, 220,240 , and $260^{\circ} \mathrm{C}$ ) and different mixing time periods $(5,6,7$, and $8 \mathrm{~h})$ has been mixed. The intended product

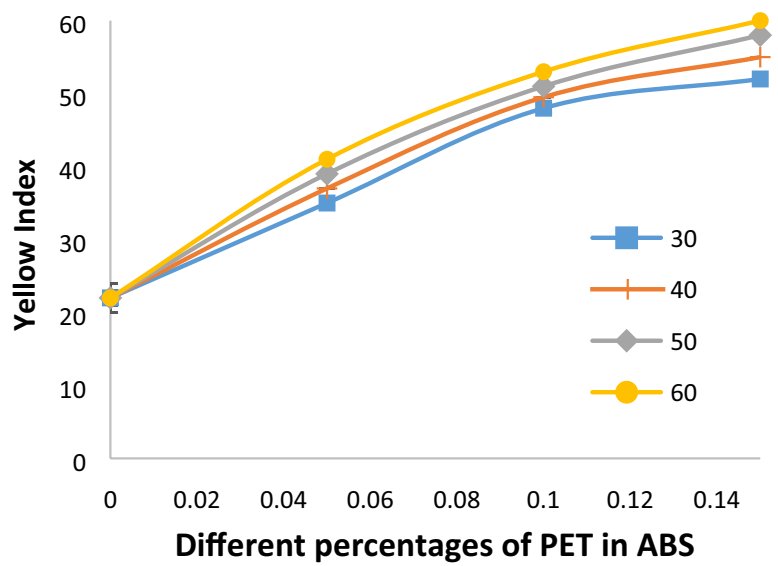

Fig. 6 Results of Yellow index Test for different percentages of PET in $A B S$ of the polymer mixture in different mixing speed

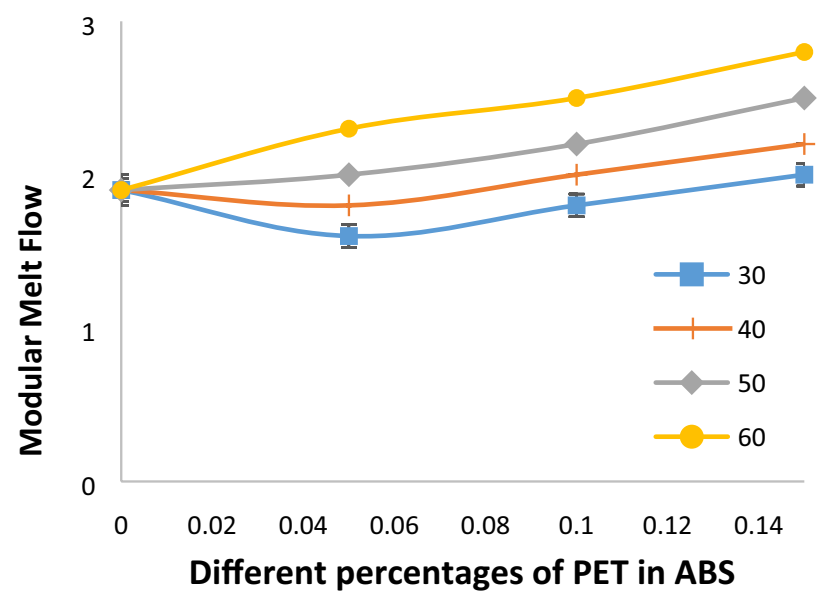

Fig. 7 Results of Modular melt flow Test for different percentages of $\mathrm{PET}$ in $\mathrm{ABS}$ of the polymer mixture in different mixing speed

ABS-PETW prepared as melted material and cooled down in two cold bathes with temperatures between 60 to 75 ${ }^{\circ} \mathrm{C}$, and 40 to $45^{\circ} \mathrm{C}$. The alloy's water dried by dryer. By using cuter it became polymer granules. By templating and pressing device, polymeric templates and sheets has been built. Finally, the physical and mechanical specifications of these templates and sheets have been measured by different devices.

\subsection{Multi-layer perceptron (MLP) network.}

The basic element of a Multi-Layer Perceptron (MLP) neural network is the artificial neuron performing a simple mathematical operation on its inputs. The inputs are the variables $\mathrm{x}_{1}, \mathrm{x}_{2}, \ldots, \mathrm{x}_{\mathrm{p}}$ and a threshold (or bias) term. Every input value is multiplied by weight, wi, after which the results are added with the bias term to produce z. finally, a known 


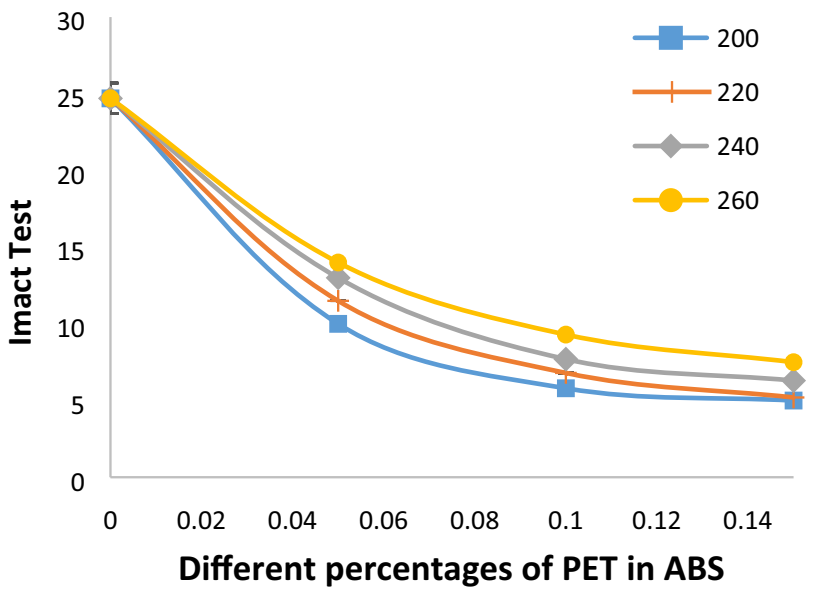

Fig. 8 Results of Impact Test for different percentages of PET in ABS of the polymer mixture in different mixing temperature

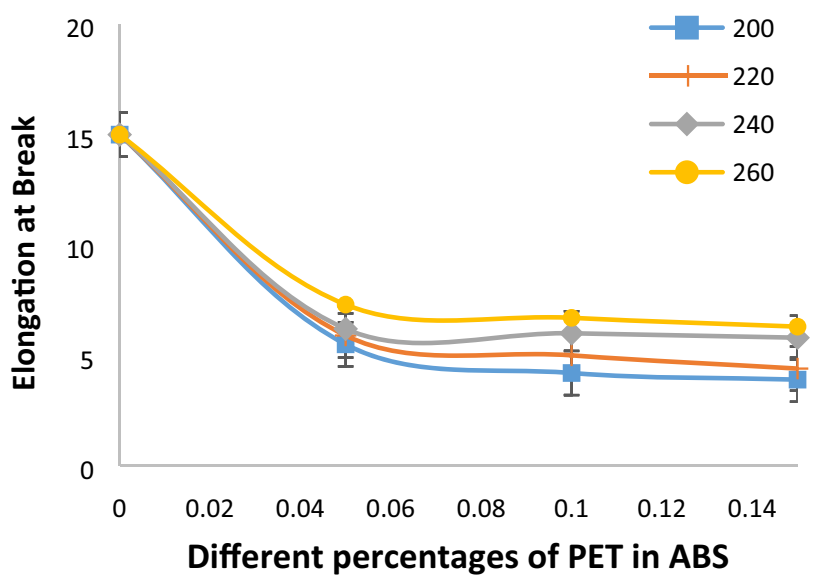

Fig. 9 Results of Elongation at Break Test for different percentages of PET in $A B S$ of the polymer mixture in different mixing temperature

activation function, $\varphi$, performs a pre-specified (non-linear) mathematical operation on the projected inputs. Different activation functions such as sigmoid or hyperbolic tangent are traditionally used for this purpose. MLP networks can conclude many neurons ordered in layers [27]. The actual processing is the job of the neurons in the hidden layer, while the neurons in the input and output layer merely distribute and collect the signals. Although, many hidden layers can be used, but using one hidden layer network is more popular for practical applications due to their simple structure. Using multilayer hidden neurons usually leads to unnecessarily large degrees of freedom. The MLP network is trained using adapting the synaptic weights using a back-propagation technique or any other optimization procedure. During training phase, the network output is compared with a desired output. The error

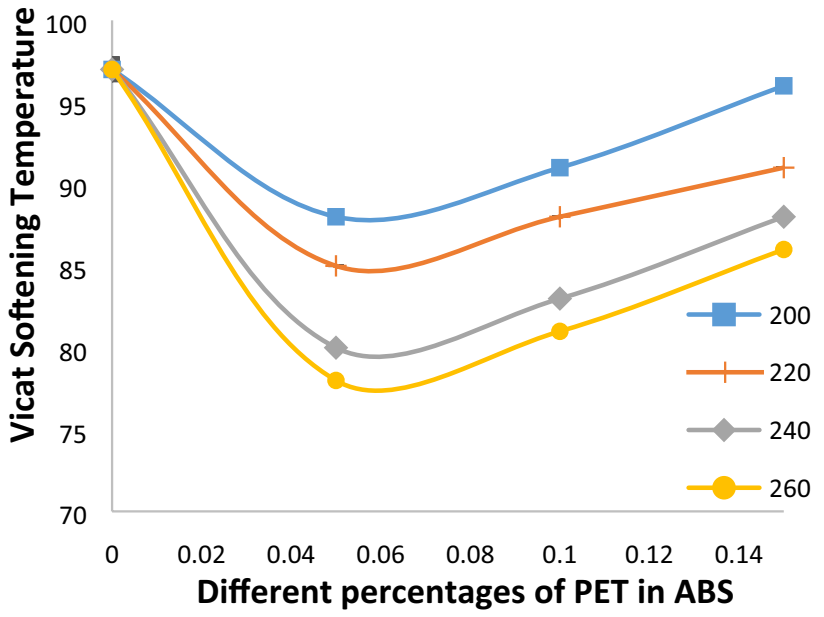

Fig. 10 Results of Vicat Softening Temperature Test for different percentages of PET in ABS of the polymer mixture in different mixing temperature

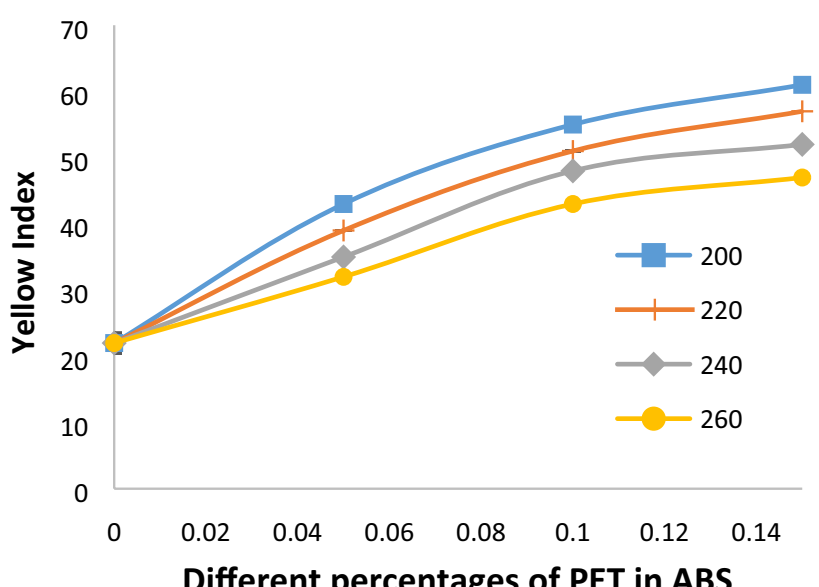

Fig. 11 Results of Yellow index Test for different percentages of PET in $\mathrm{ABS}$ of the polymer mixture in different mixing temperature

between these two signals is used to adapt the weight. This rate of adaptation may be controlled by a learning rate. A high learning rate will make the network adapt its weights quickly, but will make it potentially unstable. Setting the learning rate to zero, will make the network keep its weights constant. The steepest-decent optimization technique with constant step length parameters $(\eta)$ was employed in this article.

Additional linear weights ( $a$ 's, as shown in Fig. 1) were used in this work to accelerate the network convergence. The optimal values of these linear parameters ere updated after each back-propagation iteration using the following set of linear equations: 


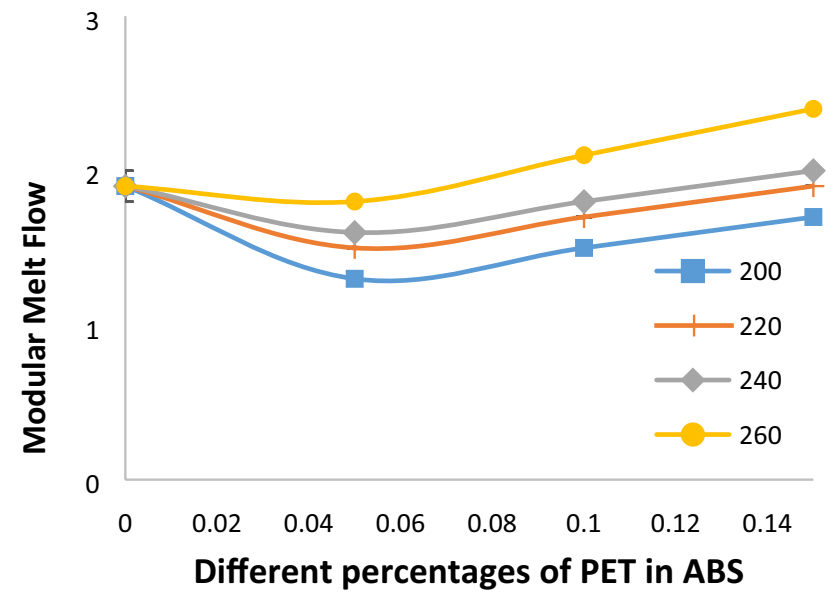

Fig. 12 Results of Modular melt flow Test for different percentages of PET in ABS of the polymer mixture in different mixing temperature

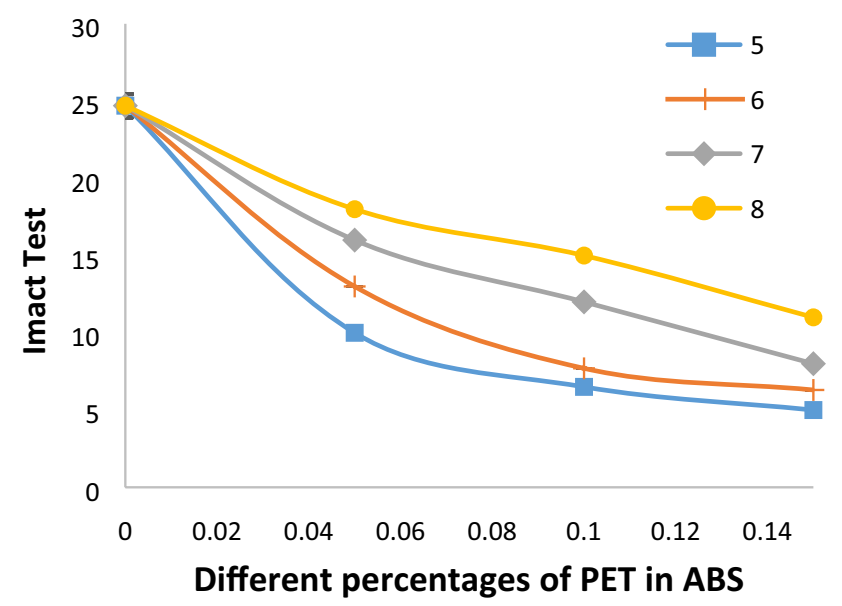

Fig. 13 Results of Impact Test for different percentages of PET in ABS of the polymer mixture in different mixing time

$\left(\phi^{T} \phi\right)_{-}^{\alpha}=\phi_{-}^{T^{y}}$

where $\phi_{i, j}=\varphi\left(z_{i, j}\right), i=1, \ldots, N \& j=1, \ldots, M$ and $y$ is the $N^{*} 1$ vector of measured values. The parameters $\mathrm{N}$ and $\mathrm{M}$ represent number of training data and number of neurons respectively. The training flow chart of such MLP network is given in our previous articles.

Similarly, other quadratic methods (e.g. Newton like techniques) may be used to compute the optimal performances of the MLP networks. The so called "line search" technique is usually used to predict the optimum learning rate compared to Newtown step length4 $(\Delta x=-G \wedge(-$ 1) g). Evidently, the quadratic methods converge faster near optimal point and not necessarily far from it. This is one of the reasons why quasi Newton techniques such as

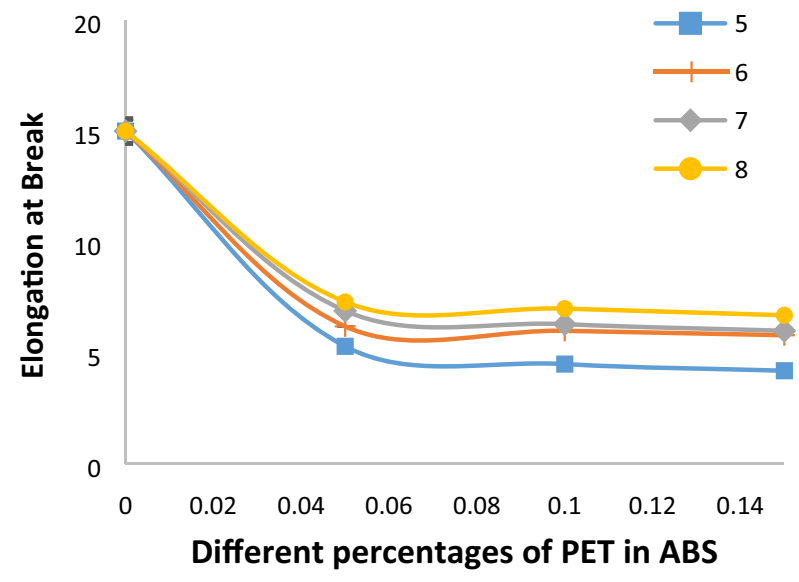

Fig. 14 Results of Elongation at Break Test for different percentages of PET in ABS of the polymer mixture in different mixing time

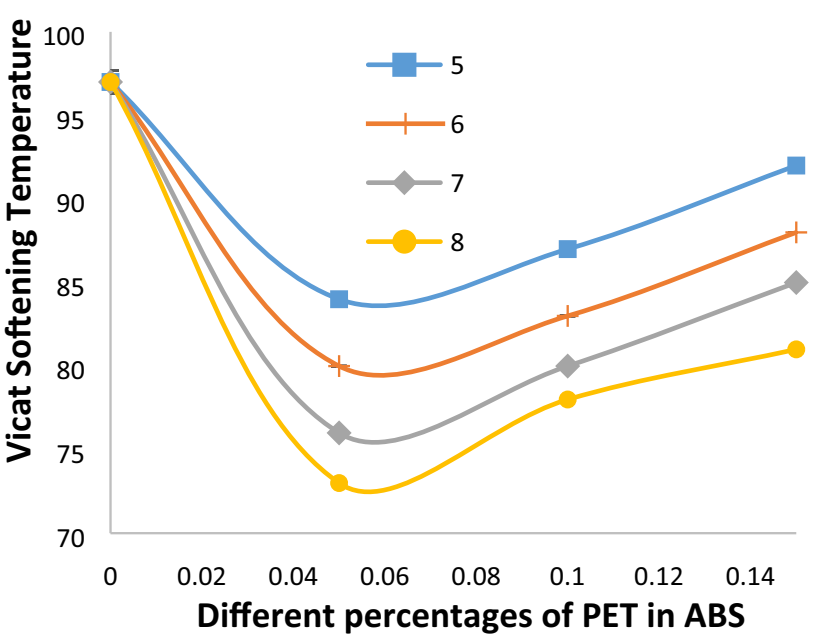

Fig. 15 Results of Vicat Softening Temperature Test for different percentages of PET in ABS of the polymer mixture in different mixing time

Levenberg-Marquadt or Guass-Newton are used. Finally, the steepest-descent methods (such as back-propagation) are more robust than the quadratic techniques when a proper step length control is used. In practice, almost never Newton like optimization methods are used for efficient neural network training because they can easily trap into sub-optimal solutions. The algorithm of the MLP network is shown in Fig. 2.

\section{SN Applied Sciences}




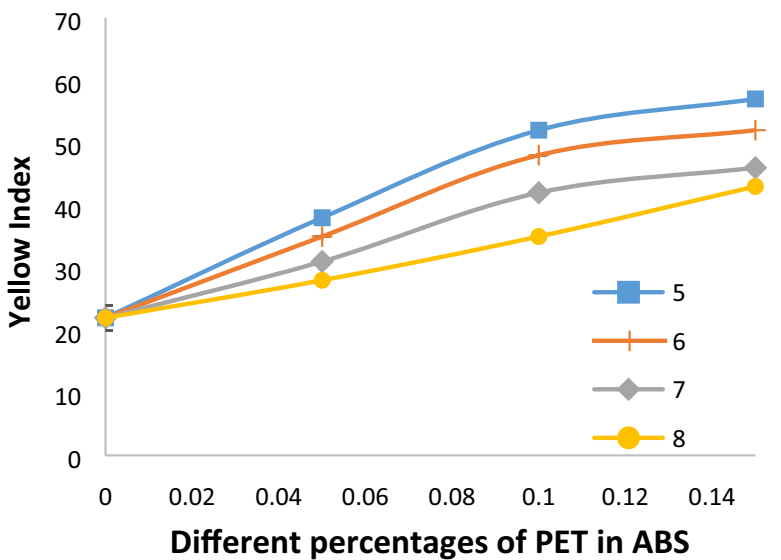

Fig. 16 Results of Yellow index Test for different percentages of PET in $\mathrm{ABS}$ of the polymer mixture in different mixing time

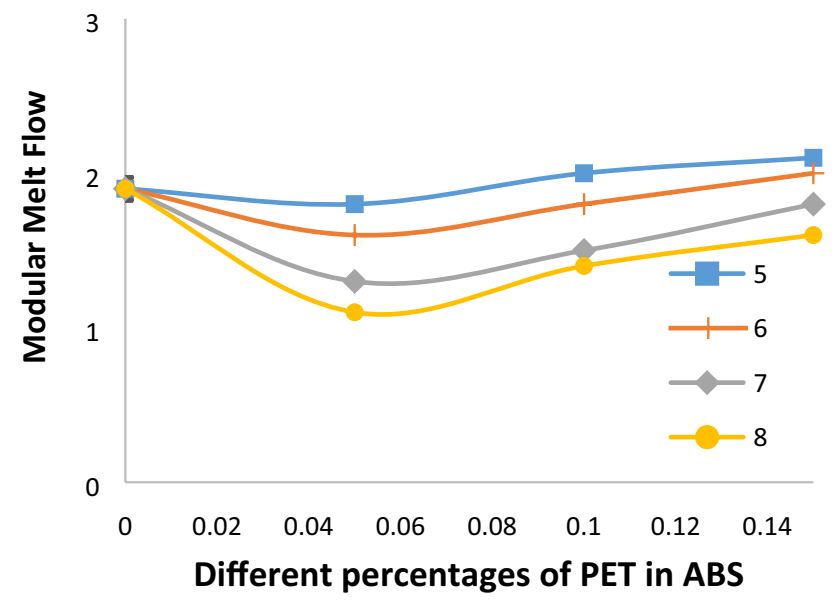

Fig. 17 Results of Modular melt flow Test for different percentages of PET in ABS of the polymer mixture in different mixing time

\section{Results and discussion}

\subsection{Results in different mixing speed}

Figure 3 shows the results for Impact test for different percentages of PETW/ABS alloy in different mixing speeds. From the figures it is clear that with increase in percentages of PETW, the amount of the Impact Test decreases. The decrement of the Impact Test profile until 20\% PETW was fast but after that the increasing in concentration of PETW has lower effect. Each test is repeated 5 times and the error bars are calculated and added to the figures.

Figure 4 shows Elongation at Break test for different mixing speeds in different percentages of PETW/ABS. with increase in PETW percentage, the amount of the Elongation Test decreases and with more increase in this percentage, the elongation at break reaches a constant amount. Increase in mixing speed has almost no effect on the Elongation at break.

Figure 5 shows relation between different percentages of PETW/ABS and mixing speeds and vicat softening temperature test. Adding PETW into pure ABS increase the amount of the vicat and with increase in percentages from 0.1 to 0.3 , the amount of the vicat increases. vicat decreases by increasing in mixing speed.

Figure 6 shows Yellow Index test results for different percentages of PETW/ABS with different mixing speeds. Because of decrease in purity of the product, by increasing the amount of the PETW, amount of the Yellow Index increases but changes on mixing speed has almost no effect on Yellow Index.

Figure 7 presents Modular Melt Flow results for different percentages of PETW/ABS in different mixing speeds. As is clear with increase in mixing speed and
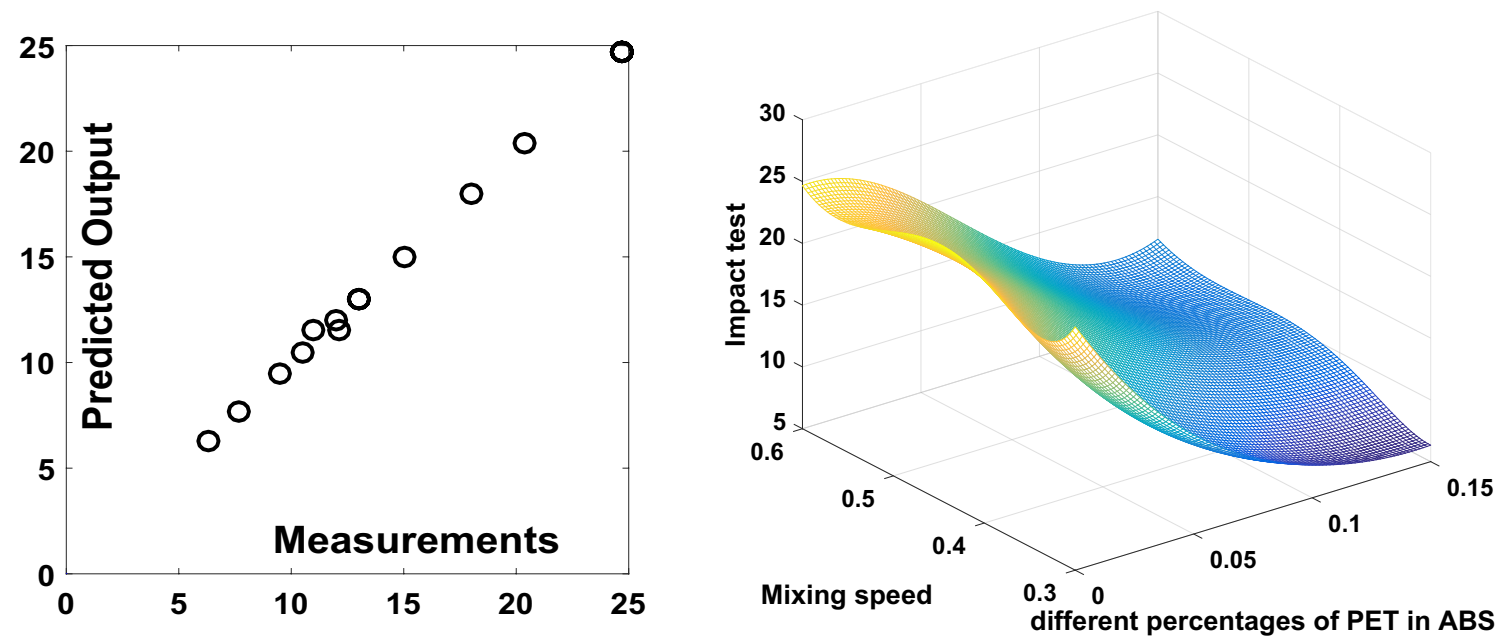

Fig. 18 Recall and generation performance of MLP networks for Impact Test data of the polymer mixture in different mixing speed 

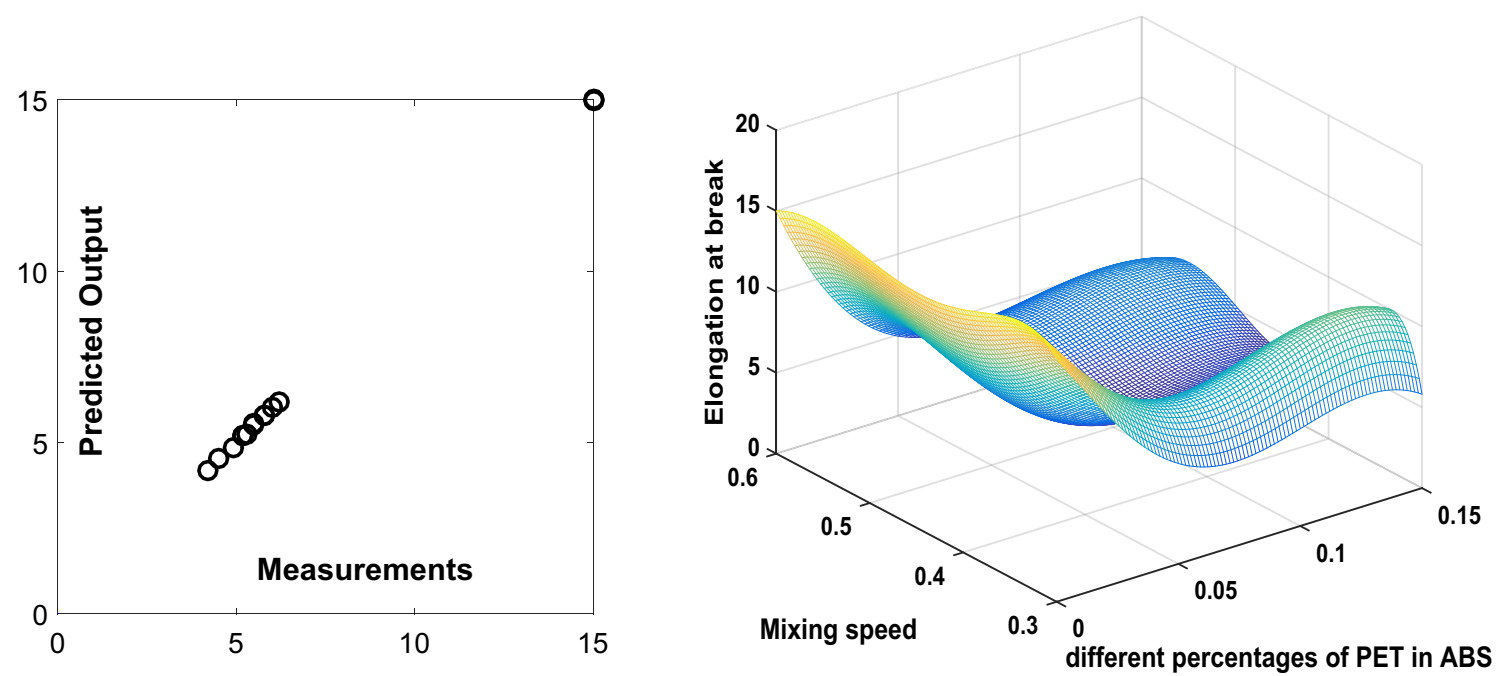

Fig. 19 Recall and generation performance of MLP networks for Elongation at Break data of the polymer mixture in different mixing speed
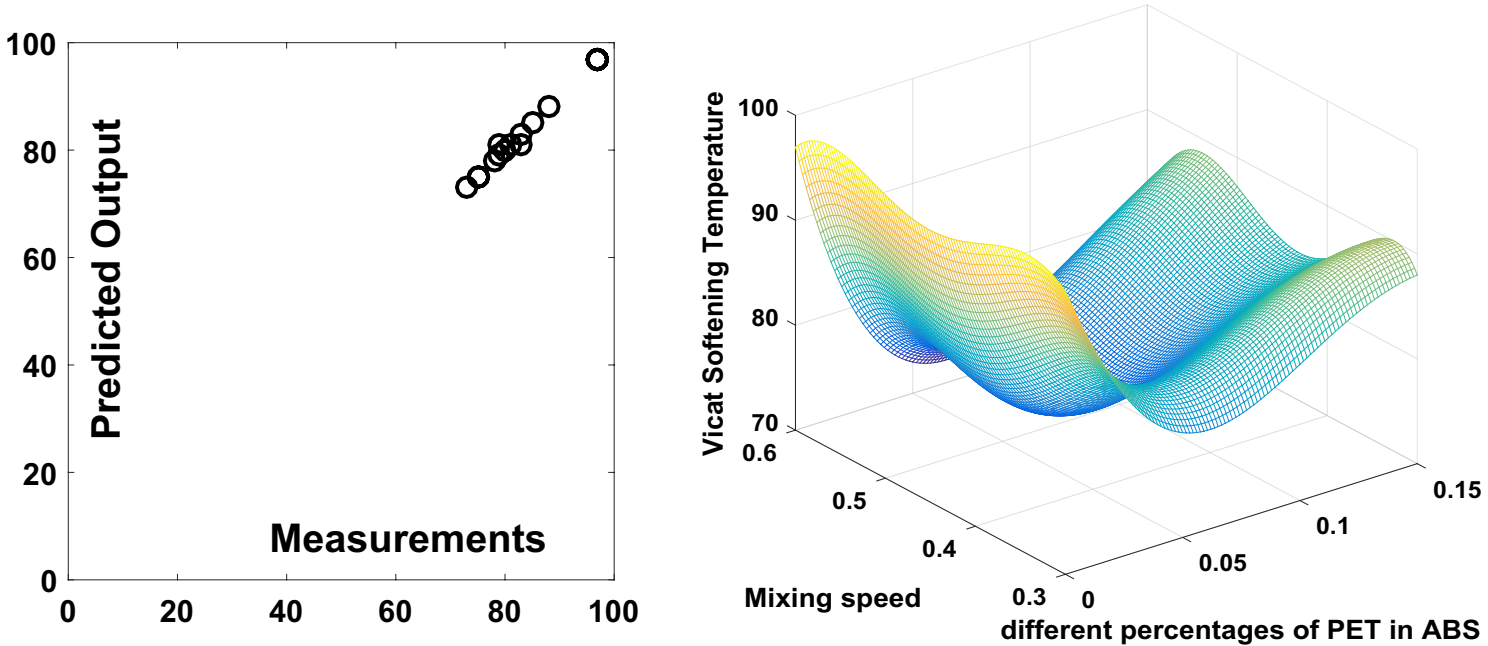

Fig. 20 Recall and generation performance of MLP networks for Vicat Softening Temperature data of the polymer mixture in different mixing speed

percentages of PETW/ABS, the amount of the Modular Melt Flow test increases. Adding PETW into pure ABS for lower mixing speeds causes Modular Melt Flow amount to decrease and higher mixing speeds causes it to increase. The increment of the Modular Melt Flow amount declares decrease in resistance against melting because of stresses done to the polymer. But in lower mixing speeds this resistance increases.

\subsection{Results in different mixing temperature}

Figure 8 is the result of Impact test for different percentages of $A B S / P E T W$ in different temperatures of mixing. It is clear that with increase in temperature in constant percentage of PET Waste, the amount of Impact Test increases and in constant temperature with increase in PET Waste, the amount of Impact Test decreases which in low percentages this decreasing has high incline and in high percentages (between 10 and 15 percentages) the incline decreases.

The amount of changes of Elongation at Break Test with mixing temperature in different percentages of PET Waste is shown in Fig. 9. The results show that with increase in PET percentage, the amount of Elongation at Break Test in constant temperature decreases but with increase in temperature, in constant percentages of PET Waste, the amount of the Elongation at Break Test increases a little. 

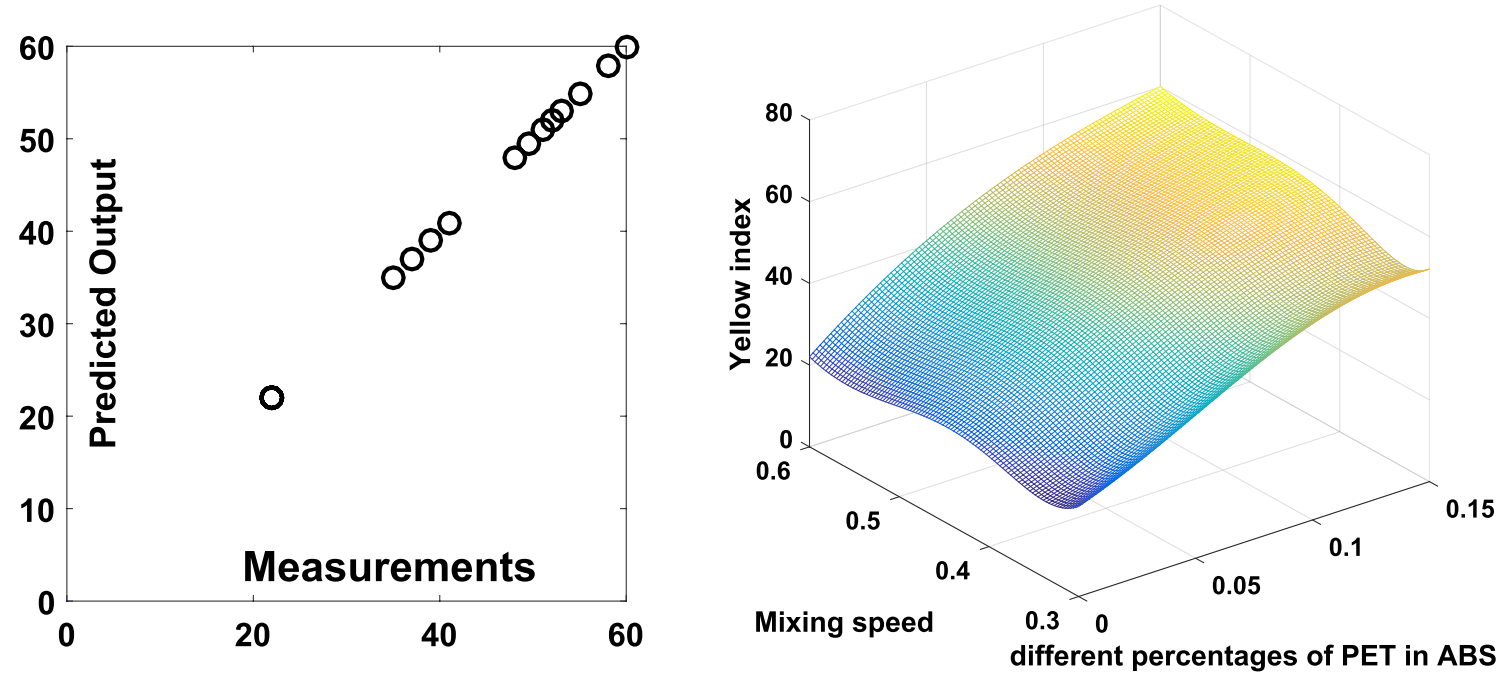

Fig. 21 Recall and generation performance of MLP networks for Yellow Index data of the polymer mixture in different mixing speed
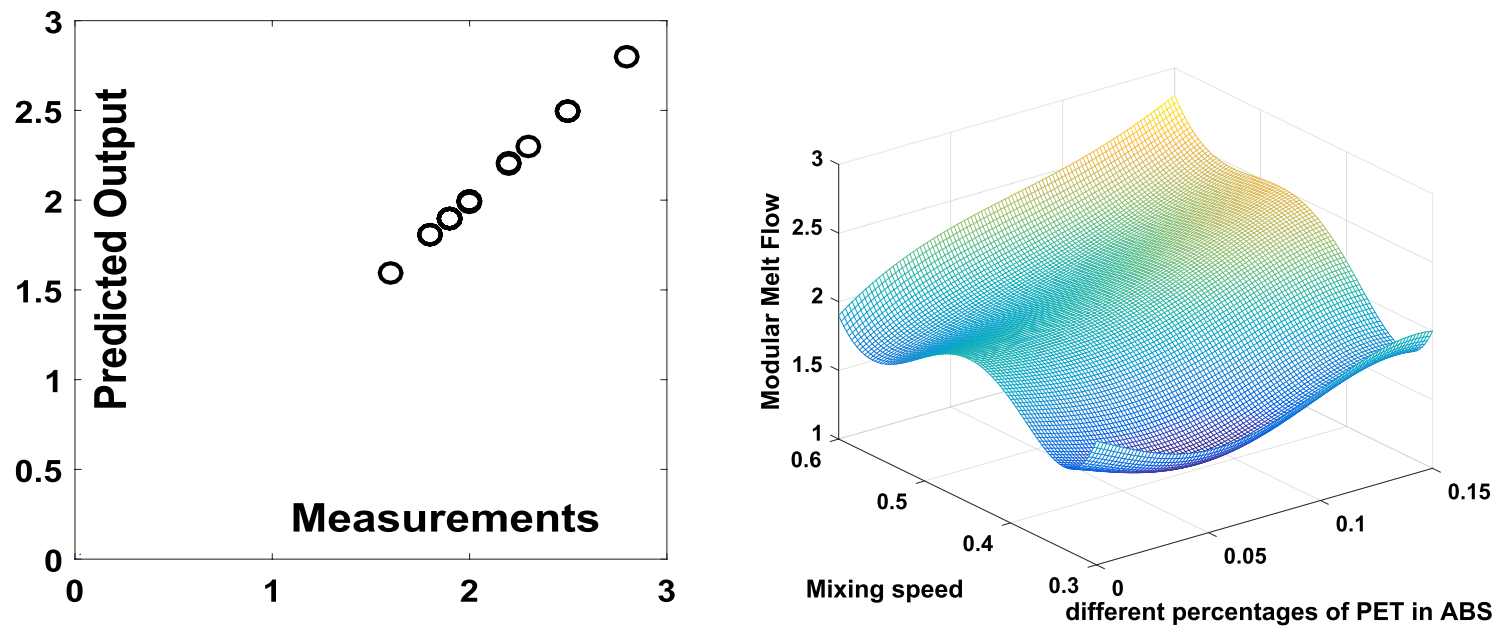

Fig. 22 Recall and generation performance of MLP networks for Modular Melt Flow data of the polymer mixture in different mixing speed
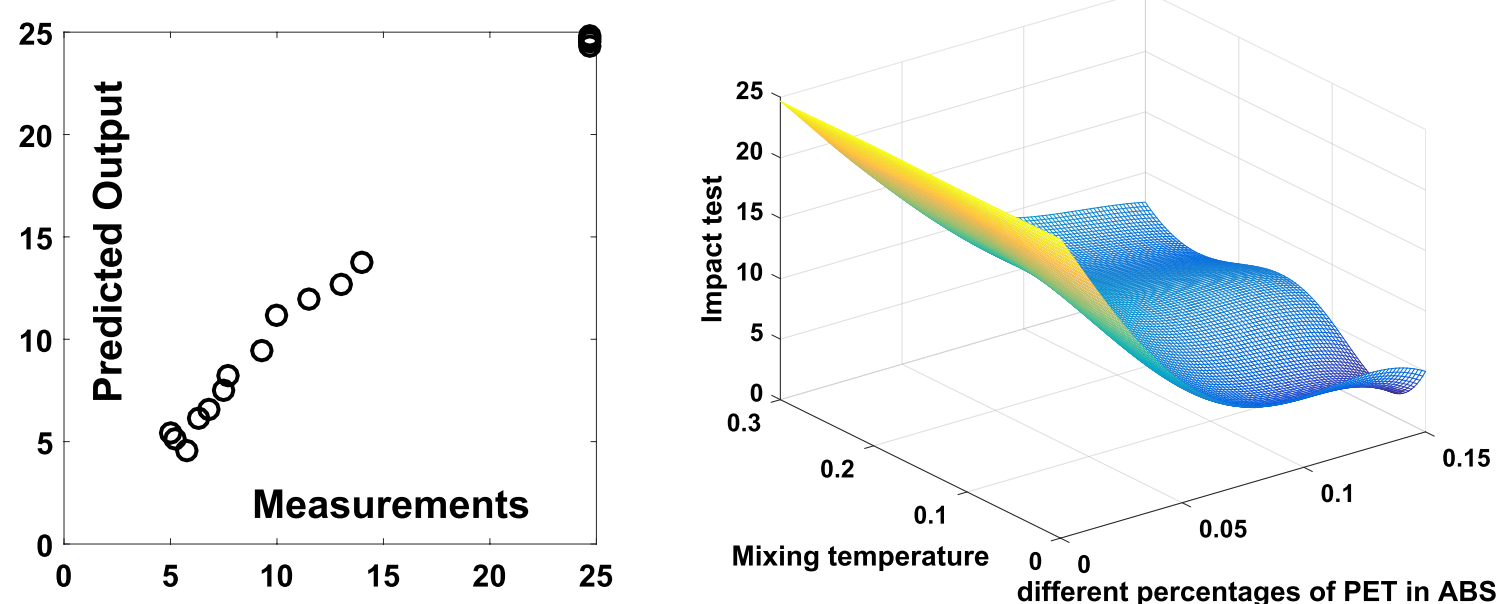

Fig. 23 Recall and generation performance of MLP networks for Impact Test data of the polymer mixture in different mixing temperature 

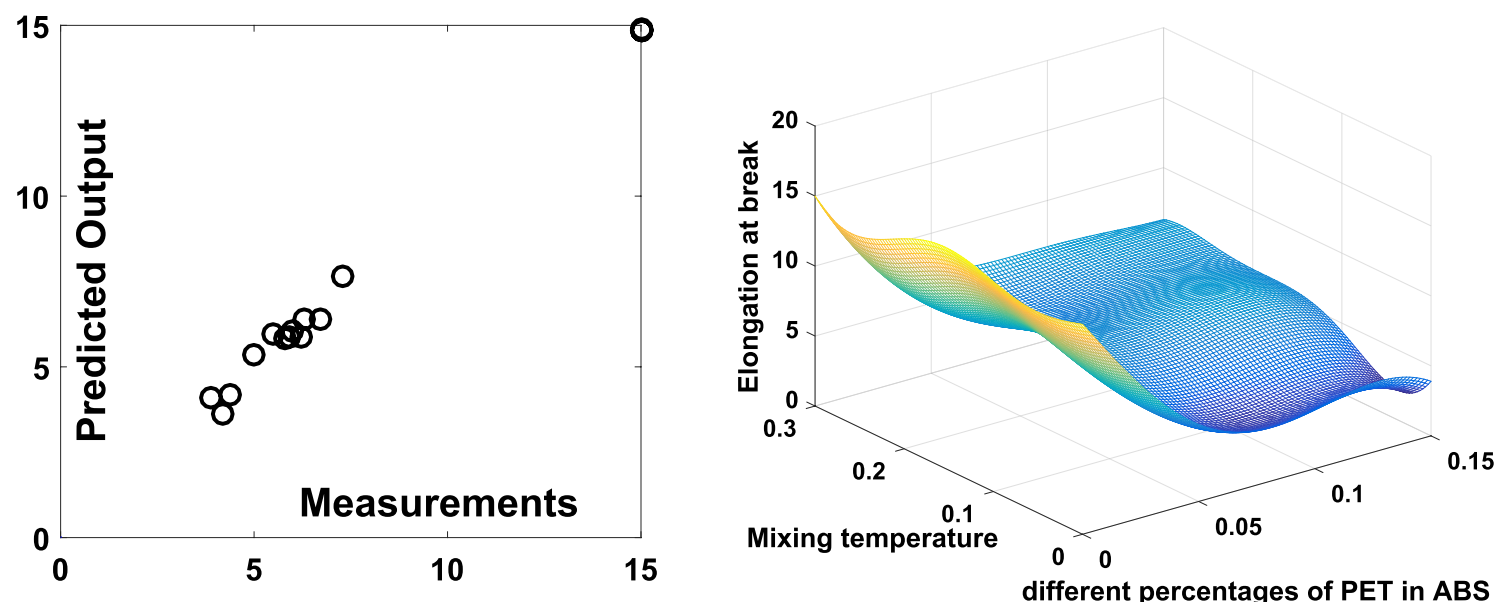

Fig. 24 Recall and generation performance of MLP networks for Elongation at Break data of the polymer mixture in different mixing temperature
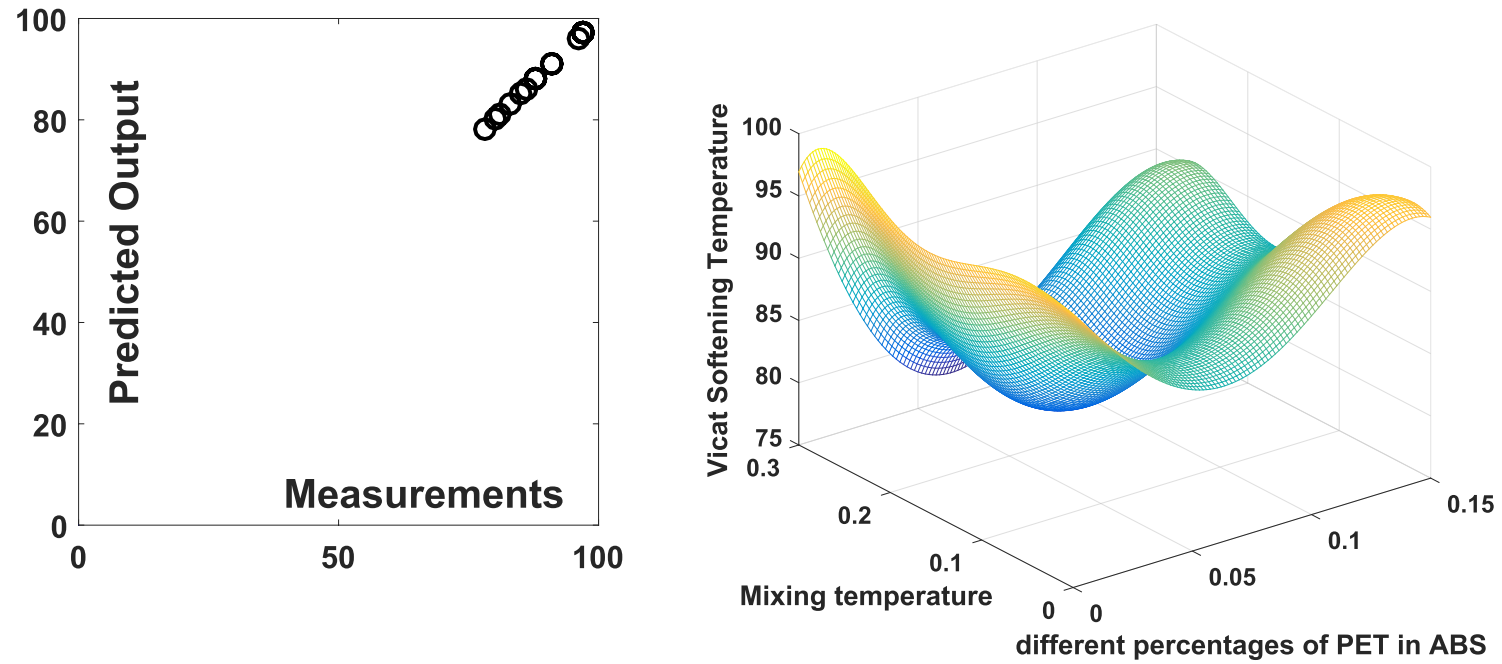

Fig. 25 Recall and generation performance of MLP networks for Vicat Softening Temperature data of the polymer mixture in different mixing temperature

Figure 10 shows the amount of Vicat Softening Temperature for different percentages of PET Waste in different temperatures. With increase in PET percentages, the amount of Vicat Softening Temperature in constant temperatures increases to reach the amount of Vicat Softening Temperature of pure ABS. in constant percentages of PET Waste with increase in temperature the amount of Vicat Softening Temperature decreases.
The results of Yellow index test for different temperatures in different percentages of PET Waste is shown in Fig. 11. With increase in PET Waste, because of increase in impurity of polymerization, Yellow index increases and with increasing temperature the amount of Yellow index decreases.

Figure 12 shows the result for Modular melt flow test for different temperatures of the mixing and different 

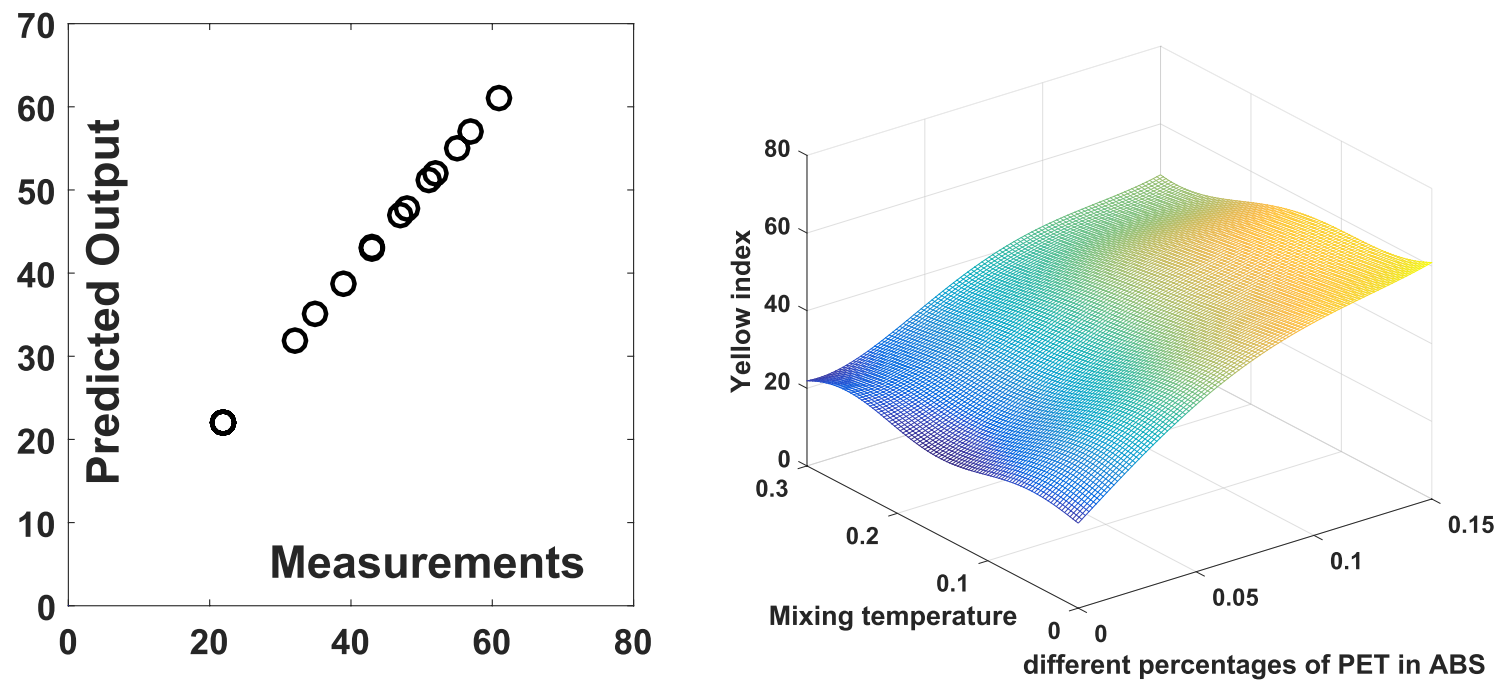

Fig. 26 Recall and generation performance of MLP networks for Yellow Index data of the polymer mixture in different mixing temperature
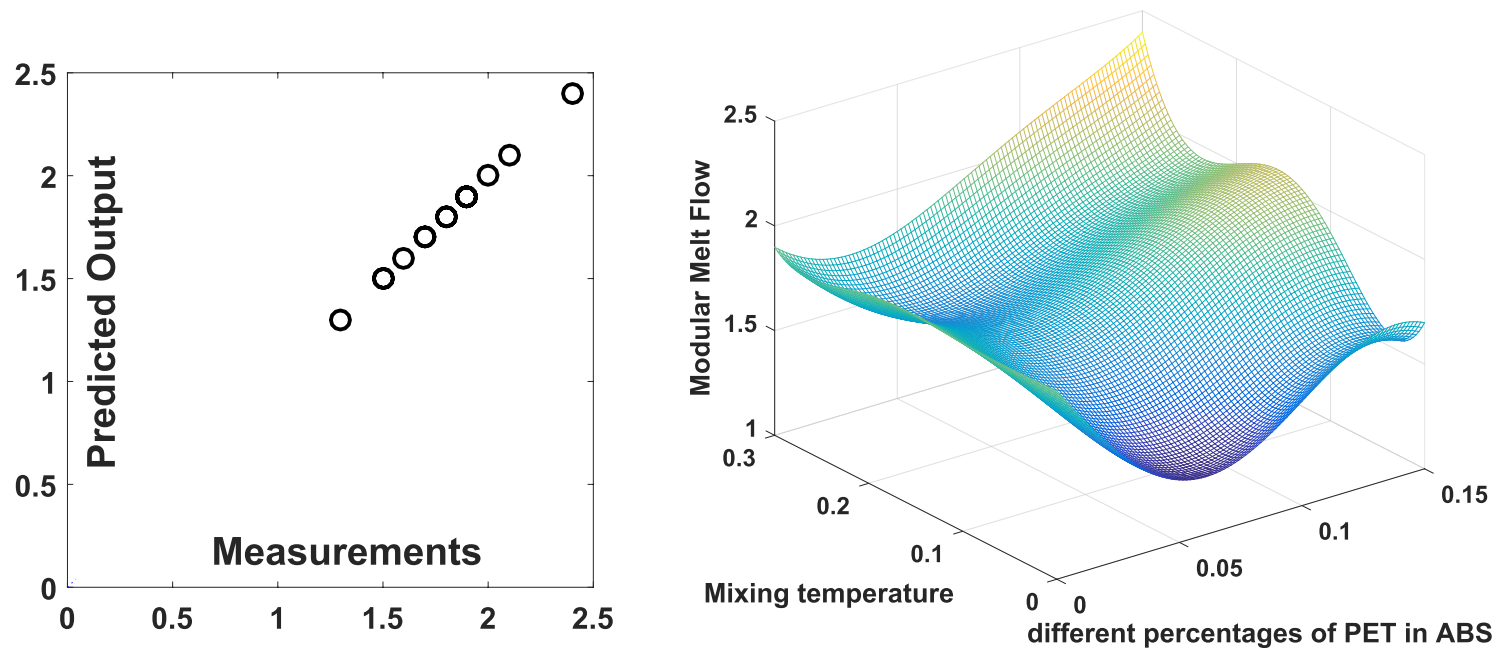

Fig. 27 Recall and generation performance of MLP networks for Modular Melt Flow data of the polymer mixture in different mixing temperature

percentages of PET Waste in ABS. with increase in temperature, in constant percentages of PET, the amount of Modular melt flow increases and in different percentages of PET, in constant temperature, the amount of Modular melt flow also increases and for temperature of $26^{\circ} \mathrm{C}$ and 15 percent the amount of Modular melt flow is more than the amount of Modular melt flow for pure ABS.

\subsection{Results in different mixing time}

In Fig. 13, the amount of change for Impact Test for different percentages of PET Waste in ABS in different times of mixing are shown. With increase in percentage of PET Waste the amount of Impact Test decreases and this decrease happens with less for shorter times and more for more time but with increase in time in constant percentage of PET Waste this amount increases.

The amount of change for Elongation at Break in different time and percentage of PET Waste are shown in Fig. 14. With increase in time in constant percentage of PET the amount of Elongation at Break increases but in constant time with increase in percentage of PET Waste, the amount of Elongation at Break is almost constant.

The amount of Vicat Softening Temperature in different percentage of PET Waste and different times of mixing are shown in Fig. 15. With increase in percentage of PET Waste in constant time, the amount of Vicat Softening Temperature increases and for constant times, with increase in percentage of PET Waste, the amount of Vicat Softening Temperature also increases rapidly. 

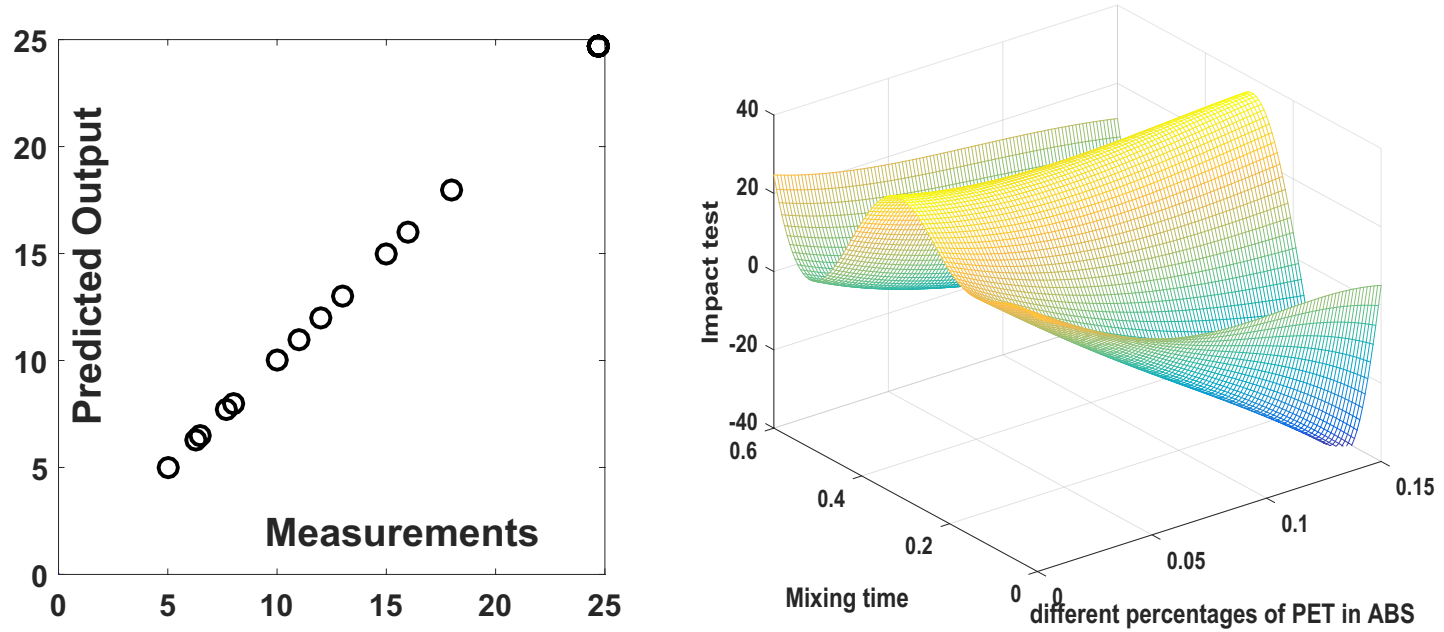

Fig. 28 Recall and generation performance of MLP networks for Impact Test data of the polymer mixture in different mixing time
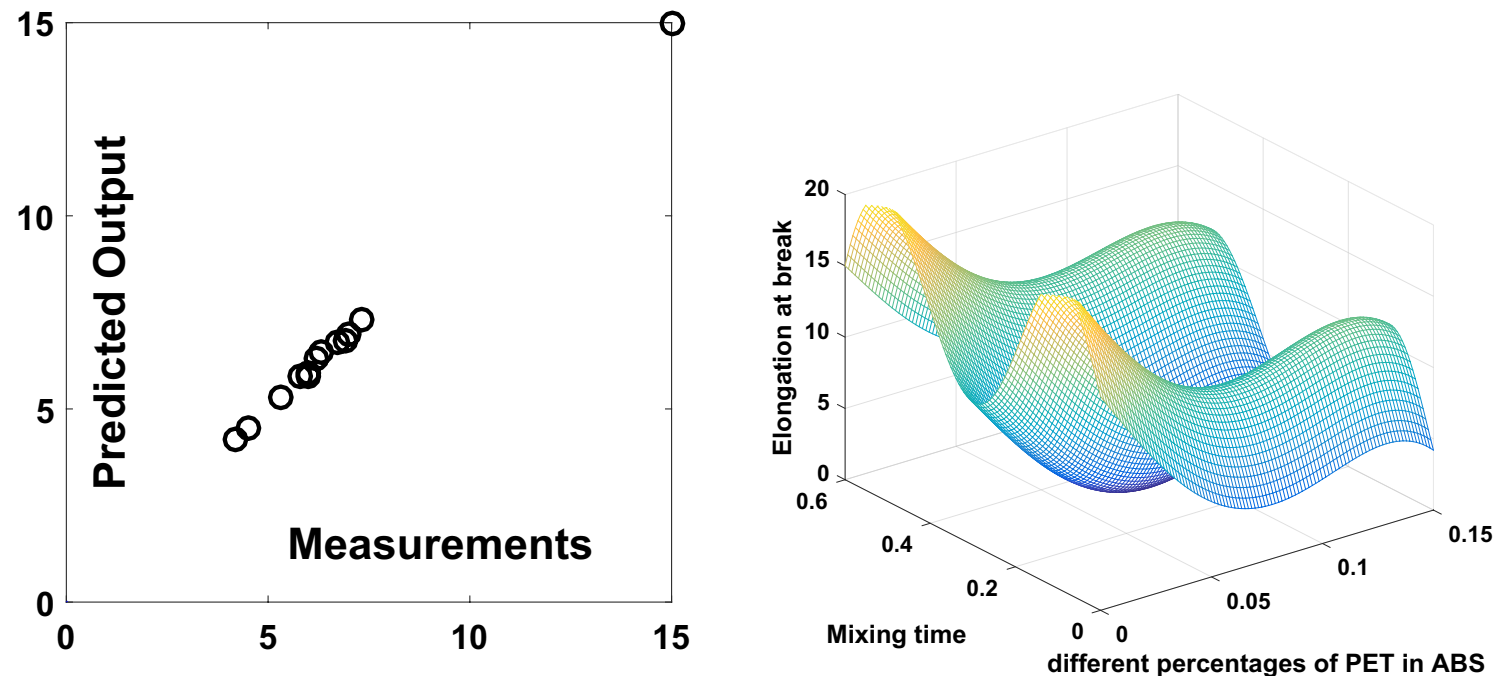

Fig. 29 Recall and generation performance of MLP networks for Elongation at Break data of the polymer mixture in different mixing time

In Fig. 16, the amount of Yellow index in different percentage of PET in different times of mixing. With increase in time for constant percentage of PET Waste the amount of Yellow index decreases and in constant time with increase in percentage of PET Waste the amount of Yellow index increases.

The amount of Modular melt flow in different percentages of PET Waste and different times are shown in Fig. 17. With increase in percentage of PET Waste the amount of Modular melt flow is almost constant and with increase in time, the amount of Modular melt flow decreases.

\subsection{Simulation results for different mixing speed}

Artificial Neural Networks simulation has been used for inputs (different percentages of PET in ABS and second input category: stirring speed, stirring temperature, stirring time) and the output is the result of different tests (Impact test, Vicar Softening Temperature, Elongation at break, Yellow index, Modular Melt Flow).

Figures 18, 19, 20, 21, 22 shows the results of simulation with MLP artificial neural networks for laboratory data gained for PETW/ABS polymer. As the amounts represent, calculated data covered laboratory data perfectly, therefore the results obtained from tests can be used for points which has not been tested. Different tests (Impact test, 

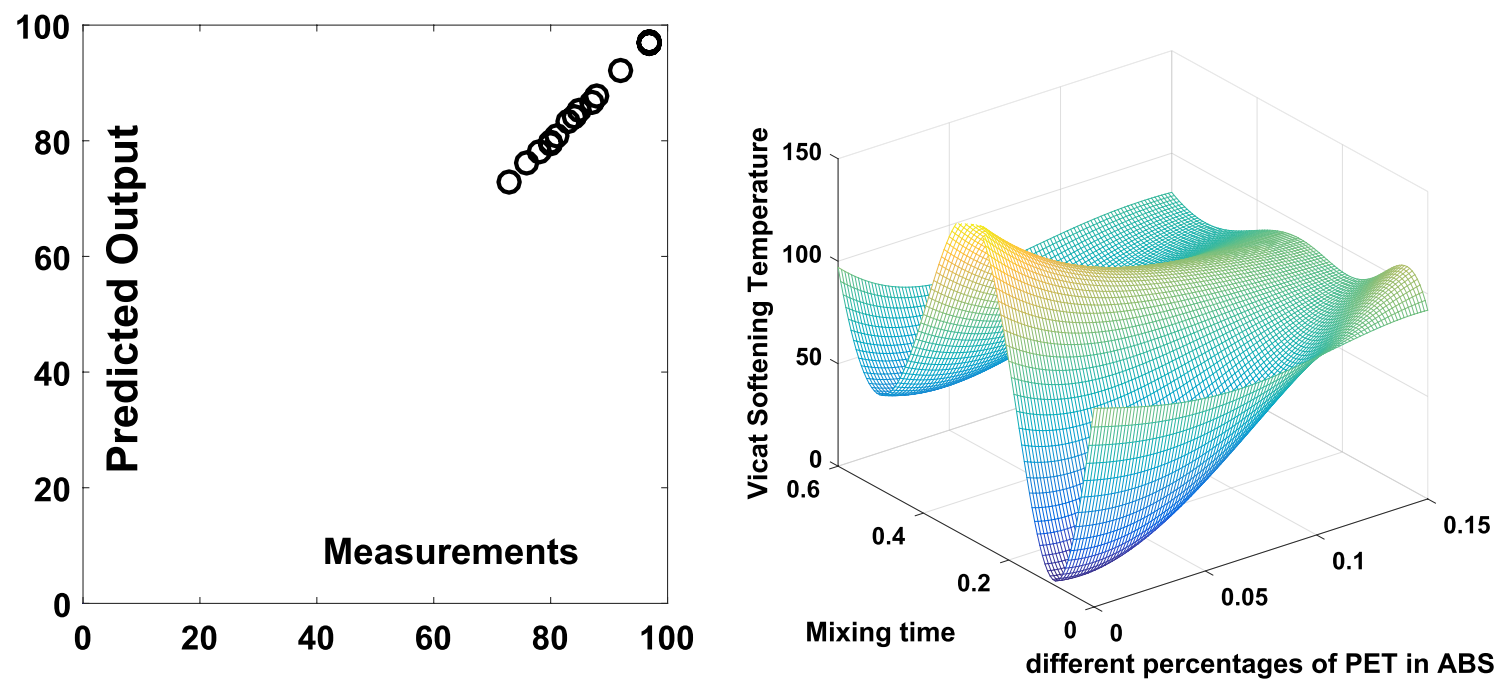

Fig. 30 Recall and generation performance of MLP networks for Vicat Softening Temperature data of the polymer mixture in different mixing $t$ time
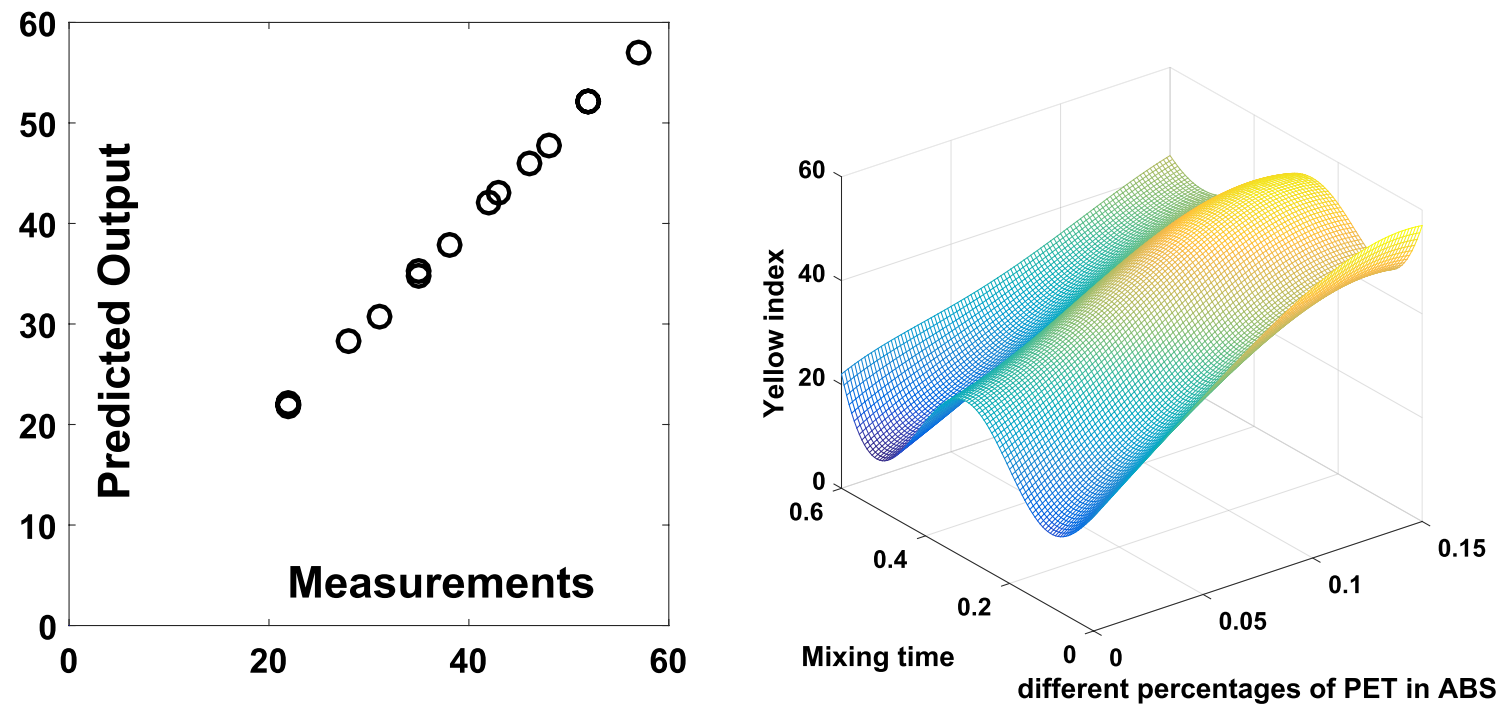

Fig. 31 Recall and generation performance of MLP networks for Yellow Index data of the polymer mixture in different mixing time

Elongation at Break, Vcat Softening Temperature, Yellow Index and Modular Melt Flow) for different percentages of Poly ethylene terephthalate wastes $(0,5,10$, and 15$)$ in ABS in different mixing speeds $(30,40,50$, and 60$)$ for preparation of this alloy has been reported in Figs. 3, 4, 5, 6, 7.

\subsection{Simulation results for different mixing temperature}

Figures 23, 24, 25, 26, 27 shows the results of simulation with MLP artificial neural networks for laboratory data gained for PETW/ABS polymer. As the amounts represent, calculated data covered laboratory data perfectly, so the results obtained from tests can be used for points which has not been tested. Different tests (Impact test, Elongation at Break, Vcat Softening Temperature, Yellow Index and Modular Melt Flow) for different percentages of Poly ethylene terephthalate wastes $(0,5,10$, and 15$)$ in $A B S$ in different mixing temperature $(200,220,240$, and 260) for preparation of this alloy has been reported in Figs. 8, 9, 10, 11, 12. 

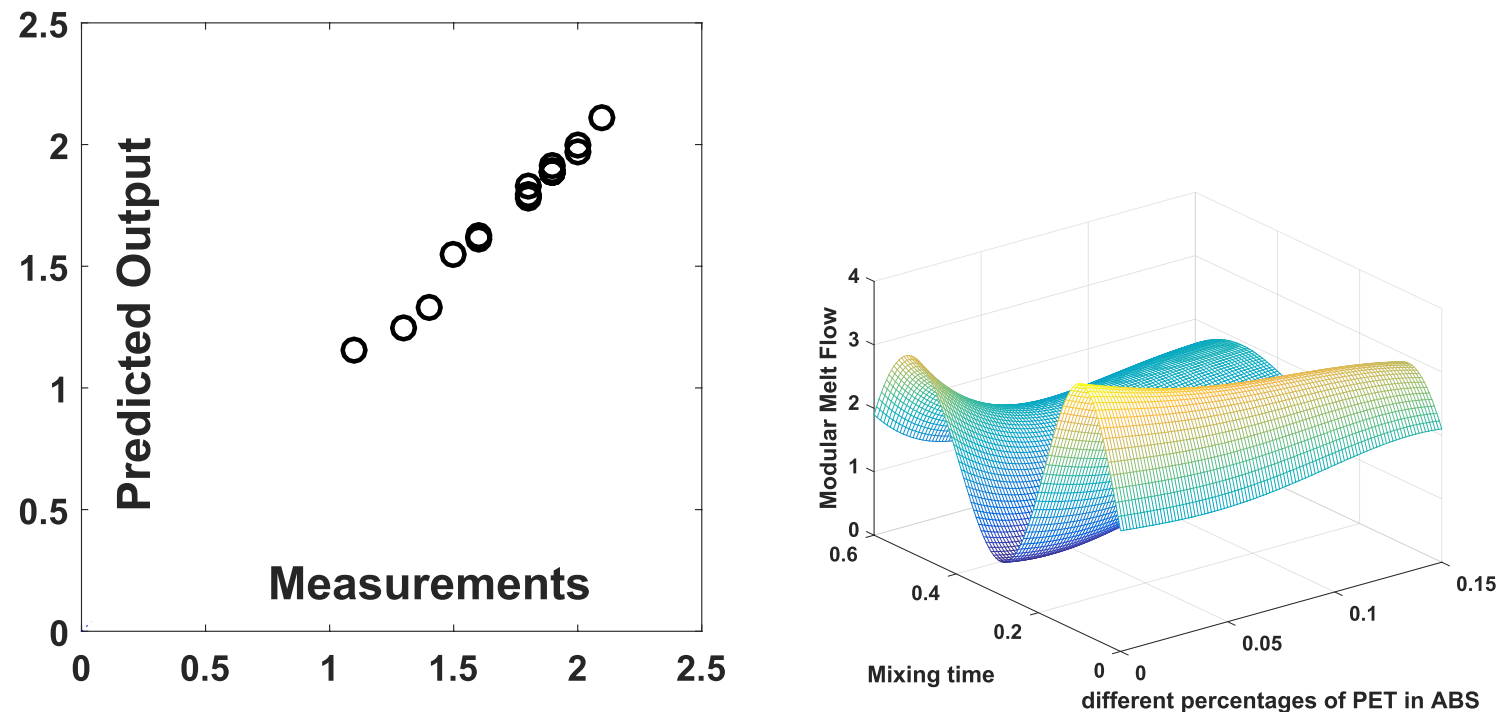

Fig. 32 Recall and generation performance of MLP networks for Modular Melt Flow data of the polymer mixture in different mixing time

\subsection{Simulation results for different mixing time}

The results of simulation by MLP networks for laboratory data gained from PETW/ABS polymer is shown in Figs. 27, $28,29,30,31,32$. Calculated data covered laboratory data perfectly as the amounts presented, therefore the results obtained from tests can be used for points which has not been tested. Impact test, Elongation at Break, Vcat Softening Temperature, Yellow Index and Modular Melt Flow has been done for different percentages of poly ethylene terephthalate wastes $(0 \%, 5 \%, 10 \%, 15 \%)$ in ABS in different mixing times $(5 \mathrm{~h}, 6 \mathrm{~h}, 7 \mathrm{~h}, 8 \mathrm{~h})$ for preparation of this ally and are reported in Figs. 13, 14, 15, 16, 17.

\section{Conclusion}

1. PET Waste has been combined with $A B S$ in different weight percentages $(0,5,10$, and 15$)$ and different tests in different situation of combining on mixed polymer has been performed.

2. Increasing PET Waste percentage in ABS in constant speed, temperature and time of the combining showed decrease in Impact Test and Elongation at Break and increase in Modular Melt Flow, vicat softening temperature, Yellow Index.

3. In constant percentages of PET:

a. By increasing the speed of the combining, vicat softening temperature and Elongation at Break decreases and Impact Test, Modular Melt Flow and Yellow Index increases. b. By increasing the temperature of the combining, vicat softening temperature and Yellow Index decreases and Impact Test, Modular Melt Flow and Elongation at Break increases.

c. By increasing the time of the combining, vicat softening temperature, Yellow Index and Modular Melt Flow decrease but Impact Test and Elongation at Break increases.

4. Simulation has been done for the collected laboratory data with the help of the MLP artificial neural networks, the results of the simulation covers the laboratory data perfectly, therefore with the help of simulation, the data can be predicted for the points which tests has not been performed.

5. The information of this article can be used as a reference for reaching the target of each tests according to changing in time and temperature and speed of the mixing.

\section{Compliance with ethical standards}

Conflict of interest The authors declare that they have no conflict of interest.

\section{References}

1. Rodríguez-Hernández AG, Muñoz-Tabare JA, Aguilar-Guzmán JC, Vazquez-Duhalt R (2019) A novel and simple method for polyethylene terephthalate (PET) nanoparticle production. Environ Sci Nano 6:2031. https://doi.org/10.1039/c9en00365g 
2. Joseph GG, Anisuzzaman SM, Moh PY, Lim E-WA (2016) Sorption and characterization studies of activated carbon prepared from polyethylene terephthalate (PET). Borneo sci 37:27-29

3. Moog D, Schmitt J, Senger J, Zarzycki J, Rexer K, Linne U, Erb T, Maier UG (2019) Using a marine microalga as a chassis for polyethylene terephthalate (PET) degradation. Microb Cell Fact 18:171. https://doi.org/10.1186/s12934-019-1220-z

4. Lee B, Onbulak S, Xu Y, Topolkaraev V, McEneany R, Bates F, Hillmyer M (2019) Investigation of micromechanical behavior and voiding of polyethylene terephthalate/polyethylene-statmethyl acrylate blends during tensile deformation. Ind Eng Chem Res 58(16):6402-6412

5. Zhou L, Lu X, Ju Z, Liu B, Yao H, Xu J, Zhang S (2019) Alcoholysis of polyethylene terephthalate to produce dioctyl terephthalate using choline chloride-based deep eutectic solvents as efficient catalysts. Gr Chemi 21(4):897-906

6. Wang $Y$, Zhang Y, Song H, Wang Y, Deng T, Hou X (2018) Zinc-catalyzed ester bond cleavage: chemical degradation of polyethylene terephthalate. J Clean Prod. https://doi. org/10.1016/j.jclepro.2018.10.117

7. Zhou L, Lu X, Ju Z, Liu B, Yao H, Xu J, Zhang S (2019) Alcoholysis of polyethylene terephthalate to produce dioctyl terephthalate using choline chloride-based deep eutectic solvents as efficient catalysts. Gr Chem 21(4):897-906

8. Baia B, Liub Y, Zhangb H, Zhoub F, Hanb X, Wangb Q, Jina H (2019) Experimental investigation on gasification characteristics of polyethylene terephthalate (PET) microplastics in supercritical water, Fuel journal. https://doi.org/10.1016/j. fuel.2019.116630

9. Kondrina KM, Kudryavtsev OS, Vlasov II, Khmelnitskiy RA, Ekimov EA (2018) High-pressure synthesis of microdiamonds from polyethylene terephthalate. Diam Relat Mater 83:190-195

10. Gasparini N, Kahmann S, Salvador M, Perea JD, Sperlich A, Baumann A, Portale G (2019) Favorable Mixing Thermodynamics in Ternary Polymer Blends for Realizing High Efficiency Plastic Solar Cells. Adv Energy Mat 9(19):1803394

11. Abtahi A, Johnson S, Park SM, Luo X, Liang Z, Mei J, Graham KR (2019) Designing $\pi$-conjugated polymer blends with improved thermoelectric power factors. J Mat Chem A 7(34):19774-19785

12. Kou Y, Cheng X, Macosko CW (2019) Polymer/Graphene composites via spinodal decomposition of miscible polymer blends. Macromolecules. https://doi.org/10.1021/acs.macromol.9b013 91

13. Parisi D ,Ahn J, Chang T, Vlassopoulos D, Rubinstein M (2020) Stress relaxation in symmetric ring-linear polymer blends at low ring fractions. Macromolecules 53(5): 1685-1693

14. Tiptipakorn S, Rimdusit S (2020) Thermal stability of shape memory polymers, polymer blends, and composites. In: Parameswaranpillai J, Siengchin S, George J, Jose S (eds) Shape memory polymers, blends and composites. Advanced structured materials. Springer, Singapore

15. Rioboo R, Demnati I, Amin Ali M, Sevkan R, De Coninck J (2019) Superhydrophobicity of composite surfaces created from polymer blends. J Colloid Interface Sci. https://doi.org/10.1016/j. jcis.2019.10.043

16. Femouillot F, Cassagnau P, Majeste J-C (2009) Uneven distribution of nanoparticles in immiscible fluids: morphology development in polymer blends. Polymer, Elsevier 50:13331350. https://doi.org/10.1016/j.polymer.2008.12.029

17. Olivera S, Muralidhara HB, Gopalakrishna KVK, Vivek CS (2016) Plating on acrylonitrile-butadiene-styrene (ABS) plastic: a review. J Mater Sci. https://doi.org/10.1007/s1085 3-015-9668-7

18. Kuo CC, Liu LC, Teng WF, Chang HY, Chien FM, Liao SJ, Kuo WF, Chen CM (2016) Preparation of starch/acrylonitrile-butadienestyrene copolymers (ABS) biomass alloys and their feasible evaluation for 3D printing applications. Compos B 86:36-39. https://doi.org/10.1016/j.compositesb.2015.10.005

19. Wang L, Wu Y, Wang Y, Li H, Jiang N, Niu K (2020) Laterally compressed graphene foam/acrylonitrile butadiene styrene composites for electromagnetic interference shielding. Compos A 133:105887. https://doi.org/10.1016/j.composites a.2020.10588

20. Zulfi A, Hapidin DA, Munir MM, Iskandar F, Khairurrijal K (2019) The synthesis of nanofiber membranes from acrylonitrile butadiene styrene (ABS) waste using electrospinning for use as air filtration media. (Paper)RSC Adv 9:30741-30751

21. Bouhfid R, Arrakhiz FZ, Qaiss A (2014) Effect of graphene nanosheets on the mechanical, electrical, and rheological properties of polyamide 6/acrylonitrile-butadiene-styrene blends. Polym Compos. https://doi.org/10.1002/pc.23259

22. Hart KR, Wetzel ED (2017) Fracture behavior of additively manufactured acrylonitrile butadiene styrene (ABS) materials. Eng Fract Mech 177:1-13. https://doi.org/10.1016/j.engfracmec h.2017.03.028

23. Quan Z, Larimore Z, Wu A, Yu J, Qin X, Mirotznik M, Chou TW (2016) Microstructural design and additive manufacturing and characterization of 3D orthogonal short carbon fiber/acrylonitrile-butadiene-styrene preform and composite. Compos Sci Technol 126:139-148

24. Cook WD, Zhang T, Moad G, Deipen GV, Cser F, Fox B, O'Shea M (1996) Morphology-property relationships in ABS/PET Blends. i. compositional effects. J Appl Polym Sci 62:1699-1708

25. Cook WD, Moad G, Fox B, Deipen GV, Zhang T, Cser F, Mccarthy L (1996) Morphology-property relationships in ABS/PET Blends. II. influence of processing conditions on structure and properties. J Appl Polym Sci 62:1709-1714

26. Paul S, Kale DD (2001) Poly (ethylene terephthalate) compatibilized by styrene maleic anhydride. J Appl Polym Sci 80:2593-2599

27. Shahsavand (2000) Optimal and adaptive radial basis function neural networks. PhD. Thesis, University of Surrey, UK

28. A. Shahsavand (2003) A novel method for predicting the optimum width of the isotropic Gaussian regularization networks. In Proceedings of the ICNN2003,

Publisher's Note Springer Nature remains neutral with regard to jurisdictional claims in published maps and institutional affiliations. 